\title{
The influence of reclaimed water recharge on 12 isomers of NP in
}

\section{groundwater}

\author{
Shiyang Yin ${ }^{1}$, Jingli Shao ${ }^{1 a}$, Zhen $\mathrm{Li}^{2}$, Honglu Liu${ }^{3}$, Yali Cui ${ }^{1}$, Qiulan Zhang ${ }^{1}$, \\ Shiyu Wang ${ }^{1}$, Xiaomin $\mathrm{Gu}^{1}$, Yong Xiao ${ }^{1}$ \\ ${ }^{1}$ Water Resources and Environmental Engineering, China University of Geosciences, Beijing, China \\ ${ }^{2}$ Shandong Provincial Key laboratory of Applied Microbiology, Ecology Institute of Shandong \\ Academy of Science, Jinan, Shandong, China \\ ${ }^{3}$ Beijing Hydraulic Research Institution, Beijing, China \\ a: 187025896@qq.com
}

Keywords: Isomers of NP; Reclaimed water; Groundwater

Abstract. Groundwater recharge using reclaimed water is considered a promising method to alleviate groundwater depletion. However, the pollutants in the reclaimed water would be recharged into groundwater during this process and pose risk to groundwater and human. In this study, 12 isomers of NP were detected in the reclaimed water and receiving groundwater in Feng River and Yanggezhuang. The variation rule of total concentration of NP was not obvious in Feng River, while the variation rule was obvious in Yanggezhuang.

\section{Introduction}

Rational use of water resources could alleviate the shortage of agricultural water resources. And with the development of urban, more reclaimed water is used for irrigation and the area using reclaimed water accounting for about $6 \%$ of the irrigated area [1]. In Beijing city, $18 \times 106 \mathrm{~m}^{3} / \mathrm{y}$ of wastewater was treated as reclaimed water from 2008 [2]. However, it is difficult to remove all the contaminants in reclaimed water completely, meaning that some of them such as endocrine disrupting chemicals, pharmaceuticals, perfluorochemicals and antibiotics were introduced into groundwater, thereby pose risks to groundwater and humans [3-5]. It is urgent to study the pollutants in reclaimed water and groundwater for risk assessment.

Nonylphenol (NP) is one of EDCs and defined as POPs due to lipotropy, high toxicity and persistence. NP was a priority pollutant in the effluent of wastewater treatment plants, which had the higher ecological risk [6]. Several researchers $[5,7]$ had studied the NP in the groundwater influenced by reclaimed water or waste water. Moreover, most of the researchers studied the NP which was the mixture of isomers and the isomers of NP in the groundwater have rarely been reported.

In this study, we conducted a detailed investigation of 12 isomers of NP to gain insight into their occurrence in reclaimed water and receiving groundwater in Beijing of China.

\section{Materials and methods}

Site description. Two representative cities were selected in Beijing of China, which were the wetland in Yanggezhuang and Feng River. In the wetland of Yanggezhuang, the reclaimed water 
(FH) and groundwater in the level of $20 \mathrm{~m}$ (FH20), $40 \mathrm{~m}$ (FH40), $60 \mathrm{~m}$ (FH60) and 80m (FH80) were sampled and in Feng River, the reclaimed water (YGZ) and groundwater in the level of $20 \mathrm{~m}$ (YGZ20), $40 \mathrm{~m}$ (YGZ40), $80 \mathrm{~m}$ (YGZ80) and 150m (YGZ150) were got in 2013. The sample sites were shown in Fig. 1.

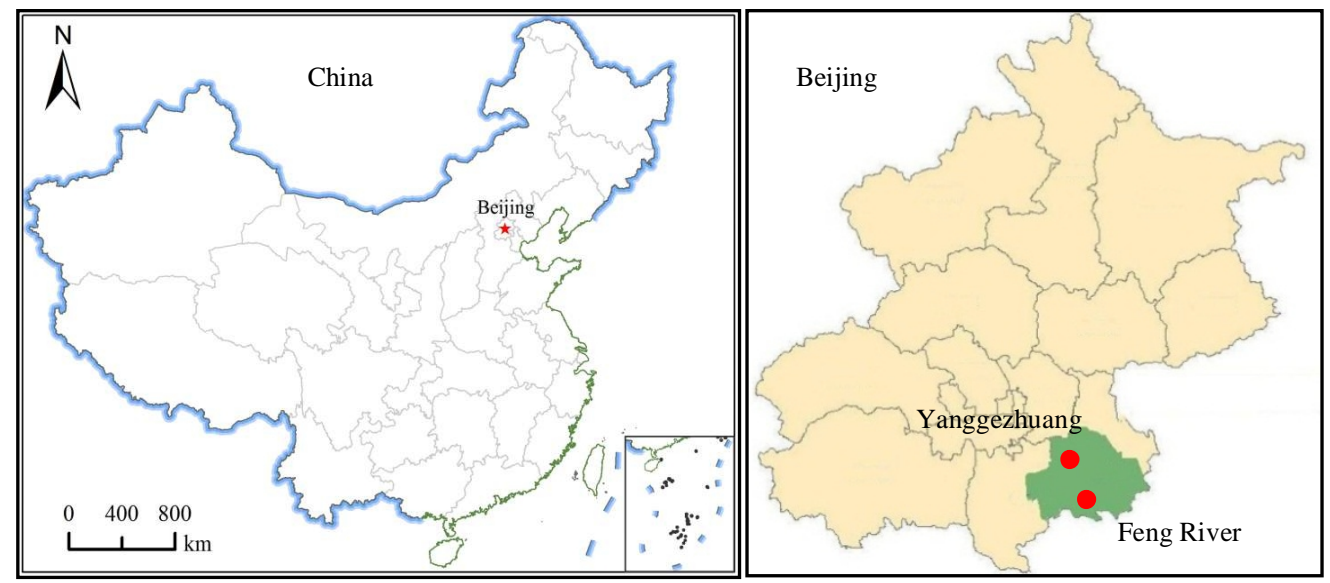

Fig. 1 Map of the sampling locations

Sampling and analysis. The methods used for sampling and analysis of were based on those reported by Wang Shiyu et al. [8]. All samples were collected $(1000 \mathrm{~mL}$ for reclaimed water and groundwater, respectively) in prewashed amber glass bottles, kept in a cooler, and transported to the laboratory.

The NP in the samples were concentrated and purified prior to analysis. $30 \mathrm{~g} \mathrm{NaCl}$ was added into $1 \mathrm{~L}$ water samples in the separatory funnel. $10 \mu \mathrm{L} \mathrm{NP}(100 \mathrm{mg} / \mathrm{L})$ standard solution was added. Then $\mathrm{H}^{2} \mathrm{SO}^{4}(1+1)$ was used to adjust the $\mathrm{pH}$ to less than 2. $20 \mathrm{~mL}$ methylene chloride was used to extract. The extracts for three times were combined and dried using anhydrous $\mathrm{Na}^{2} \mathrm{SO}^{4}$ to $1 \mathrm{~mL} .10$ $\mu \mathrm{L}$ internal standard of naphthyl-d8 $(50 \mathrm{mg} / \mathrm{L})$ was added and dilute to $1 \mathrm{~mL}$ with dichloromethane.

The concentrations of NP were determined using a gas chromatography/mass spectromrtry (Agilent Technologies Inc., USA).

Optimization of GC separation conditions: Inlet temperature: $250{ }^{\circ} \mathrm{C}$; carrier gas He; column flow rate of $1 \mathrm{~m} \mathrm{~L} / \mathrm{min}$; injection side: splitless; MS interface temperature: $280{ }^{\circ} \mathrm{C}$. Temperature program: $50{ }^{\circ} \mathrm{C}(1 \mathrm{~min}) \stackrel{5{ }^{\circ} \mathrm{C} / \mathrm{min}}{\longrightarrow} 150{ }^{\circ} \mathrm{C}(1 \mathrm{~min}) \stackrel{2{ }^{\circ} \mathrm{C} / \mathrm{min}}{\longrightarrow} 180{ }^{\circ} \mathrm{C}(5 \mathrm{~min}) \stackrel{12^{\circ} \mathrm{C} / \mathrm{min}}{\longrightarrow} 230{ }^{\circ} \mathrm{C}(1 \mathrm{~min})$. The test conditions of MSD: Ion source temperature: $230{ }^{\circ} \mathrm{C}$; quadrupole temperature: $150{ }^{\circ} \mathrm{C}$; scan range: $50 \sim 300 \mathrm{amu}$; signal acquisition mode: Scan and sim mode.

Standards of NP. Standards of NP and naphthyl-d8 were purchased from Dr Ehrenstorfer GmbH Inc. (Germany). Stock solutions of NP and naphthyl-d8 were prepared in dichloromethane. All solutions were stored at $-18^{\circ} \mathrm{C}$ in the dark until analysis.

Statistical Analysis. Data were analysis using origin and excel.

\section{Results and discussion}

Occurrence of NP in the reclaimed water and groundwater of Feng River. Fig. 2 is the occurrence of the isomers of NP in reclaimed water and different level of groundwater in Feng River. The total concentration of NP ranged from ND to $632.9 \mathrm{ng} / \mathrm{L}$ in one sample, while the average was $398.9 \pm 259.4 \mathrm{ng} / \mathrm{L}$. The total concentration of NP changed obviously with the depth of groundwater, which may be related to the lithologic character of monitoring wells and the recharge sources of groundwater $[9,10]$. Chloridion is often used as a tracer, so in order to study the recharge 
relationship, the chloridion in the reclaimed water and groundwater was detected. The concentration of chloridion in the FH20 sample was $31.7 \mathrm{mg} / \mathrm{L}$, which was $18.5 \%$ of the concentration in the reclaimed water, lower than the concentration in FH40 and FH80 samples and was 22.2\% and $19.9 \%$ of the concentration in FH40 and FH80 samples, respectively. That means the source of replenishment of $\mathrm{FH} 20$ was mainly atmosphere precipitation in this area and seepage of surface water was secondary. That was consistent with the occurrence of NP in FH20. As shown in Fig. 2, the concentration of NP in FH20 was relatively low, due to the groundwater mainly from atmosphere precipitation and in the rainfall, the NP was relatively scarce. The concentrations of chloridion in the groundwater of FH40 and FH80 were roughly similar with the reclaimed water, which means the groundwater of FH40 and FH80 replenished by surface water. The total concentration of NP in the groundwater of FH40 was $629.5 \mathrm{ng} / \mathrm{L}$ and that in the reclaimed water of FH was $632.9 \mathrm{ng} / \mathrm{L}$. The total concentration of NP in the groundwater of FH80 was $365.7 \mathrm{ng} / \mathrm{L}$, which decreased by $41.9 \%$ contrast to FH40. That may be due to the adsorption of clay. The depth of groundwater of FH150 was higher, contact less with the rainfall and surface water and update slowly. The groundwater of FH150 was not polluted by NP.

As shown in Fig. 2, except NP1, all the other isomers of NP were detected. NP5, NP7, NP9, NP11 and NP12 were detected in all the samples. The largest variations of NP5, NP7, NP9, NP11 and NP12 were $17.89 \%, 147.57 \%, 136.31 \%, 16.03 \%$ and $110.48 \%$, respectively. The variations of NP5 and NP11 were less. The highest concentration of the isomers was NP12 detected in the groundwater of FH40, which was $103.7 \mathrm{ng} / \mathrm{L}$.

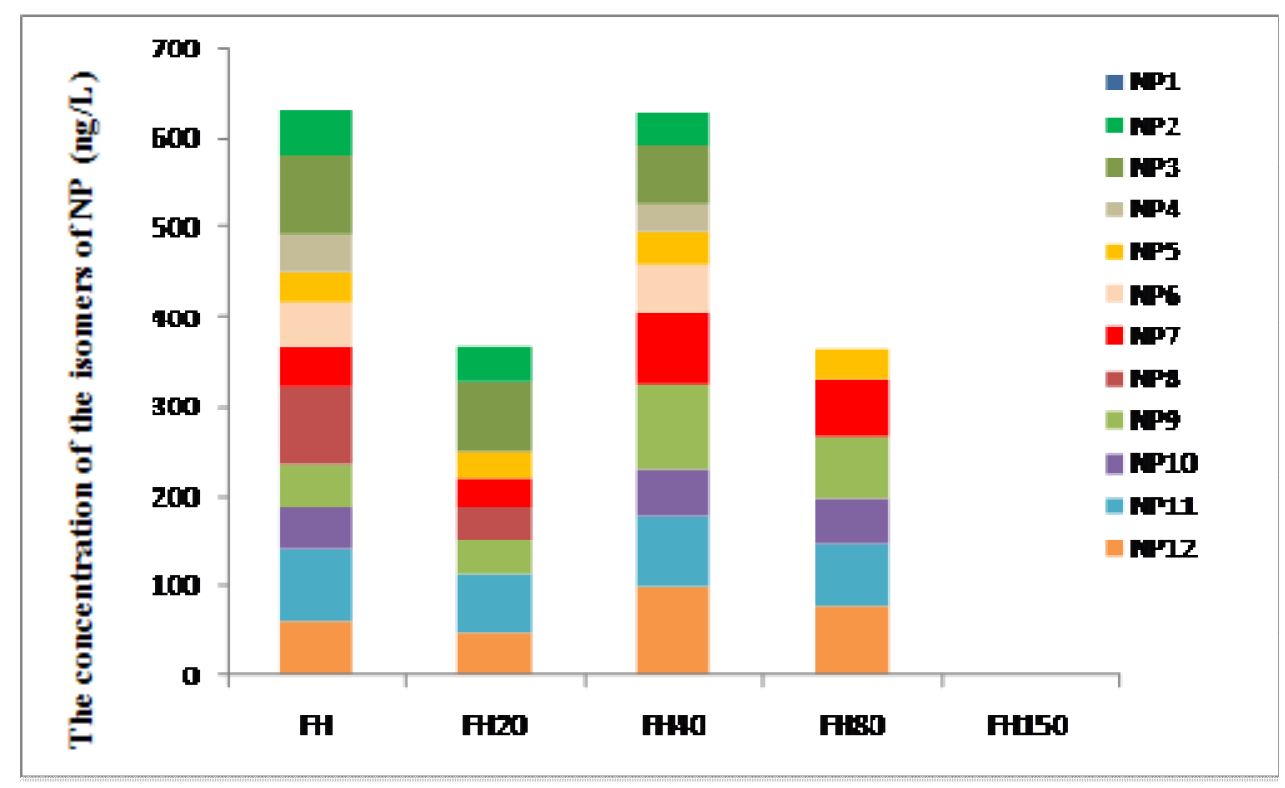

Fig. 2 The occurrence of NP in the reclaimed water and groundwater of Fenghe

Occurrence of NP in the reclaimed water and groundwater of Yanggezhuang. Fig. 3 is the occurrence of the isomers of NP in the reclaimed water and different level of groundwater in Yanggezhuang. The total concentration of NP ranged from 68.6 to $609.1 \mathrm{ng} / \mathrm{L}$ and the average concentration was $392.6 \pm 203.2 \mathrm{ng} / \mathrm{L}$. The concentration of NP decreased significantly in the vertical direction, that was different from Feng River. The groundwater of YGZ80 had been polluted. The district is located at downstream of the alluvial and diluvial fan of Yongding River and the average particle-size reduced and stratums increased gradually from the northwest to the southeast. The lithology was mainly gray and yellow clay, clayey silt and sandy silt with silty-fine sand, coarse sand and gravel. NP would adsorb on clay soil strongly and the transformation downward would decrease. The difference of total concentrations of NP in the 
groundwater of YGZ20 and YGZ60 was not big and the rate of change was lower than 22.4\%. The reduction of total concentration in the groundwater from YGZ60 to YGZ80 was obvious and the rate of change was $80.5 \%$. That may be because the strong adsorption of soil.

As shown in Fig. 3, NP2, NP3, NP5, NP9, NP11 and NP12 were detected in no less than $80 \%$ of the samples, the detection frequencies of NP7 were 60\%, the detection frequencies of NP1, NP6 and NP8 were $60 \%$, while the detection frequencies of NP4 and NP10 were 20\%. Except in the groundwater of YGZ80, NP2, NP5, NP9, NP11 and NP12 were detected in all the samples and the largest variations of concentrations of NP2, NP5, NP9, NP11 and NP12 were 16.5\%, 12.7\%, 64.8\%, $9.9 \%$ and $26.9 \%$, respectively. In the groundwater of YGZ80, only NP3 was detected, which was $76.8 \mathrm{ng} / \mathrm{L}$. The concentrations of NP3, NP9, NP11 and NP12 were higher. The average concentration of NP7, which had larger estrogenic effects, was $24.7 \mathrm{ng} / \mathrm{L}$.

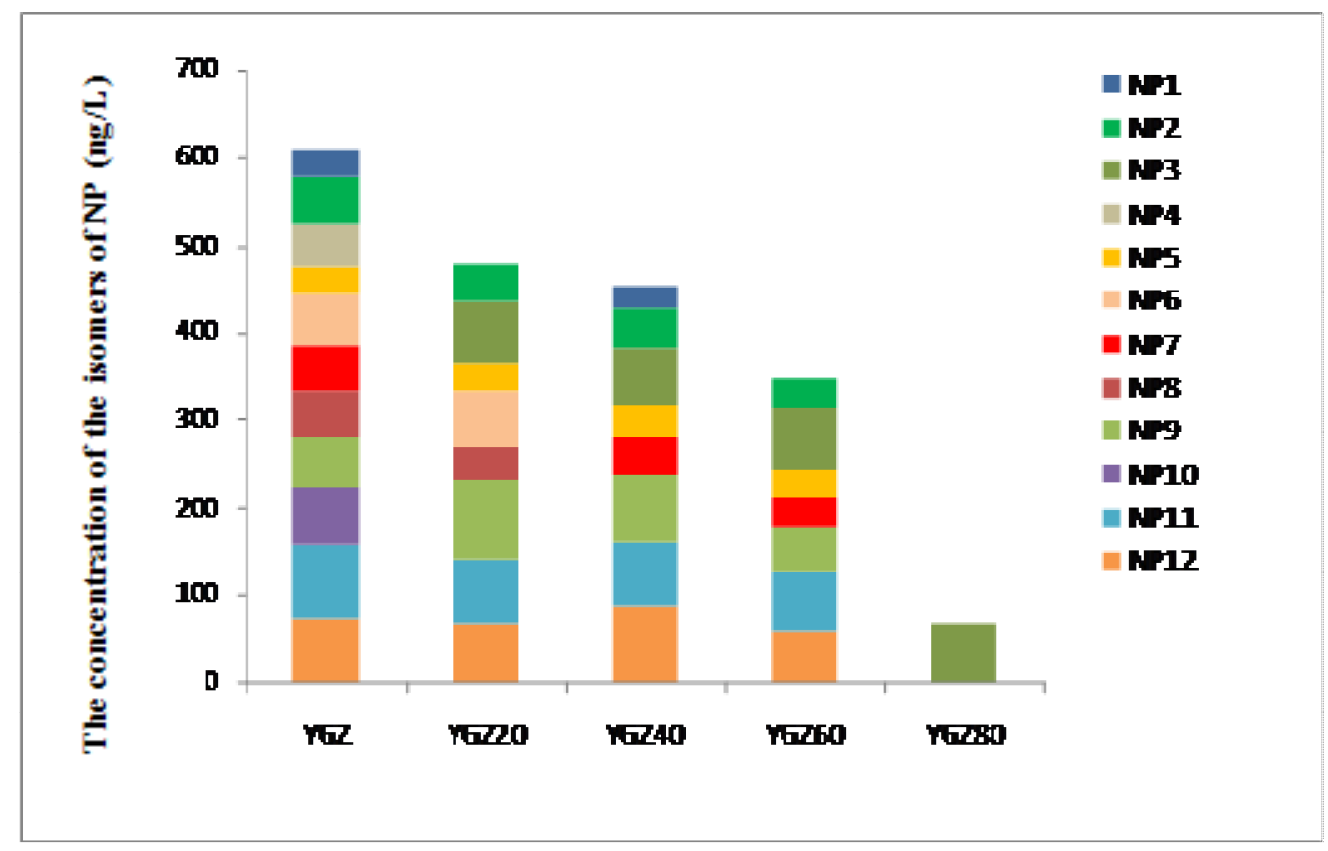

Fig. 3 The occurrence of NP in the reclaimed water and groundwater of Yanggezhuang

\section{Conclusion}

The occurrence of isomers of NP in reclaimed water and receiving groundwater of Feng River and Yanggezhuang in Beijing of China were investigated. There was no obvious variation rule for the total amount of NP in different depth of groundwater. The transformation of NP was influenced by many factors, such as infiltration of rainfall and adsorption of clay. The highest concentration of the isomers was NP12 detected in the groundwater of FH40. The variation of total concentration of NP in different depth of groundwater is obvious in Yanggezhuang. From the surface water to the groundwater in the level of $80 \mathrm{~m}$, the concentration of NP decreased step by step, mainly due to the adsorption of clay. The detection frequencies of NP2, NP3, NP5, NP9, NP11 and NP12 were more than $80 \%$.

\section{Acknowledgments}

The authors thank the Special Water Resources Research Funds for Public Welfare (No. 201101051) and the national youth fund (No. 41301019) for the financial support of this work. 


\section{Reference:}

[1] Wenyong Wu, S. Y., Honglu Liu, et al. (2013) Spatial structure and distribution characteristics of soil heavy metals in wastewater irrigation district. Transactions of the Chinese Society of Agricultural Engineering (Transactions of the CSAE). 29 165-173.

[2] Zheng, F. D., Liu, L. C., Li, B. H., Yang, Y. and Guo, M. L. (2015) Effects of Reclaimed Water Use for Scenic Water on Groundwater Environment in a Multilayered Aquifer System beneath the Chaobai River, Beijing, China: Case Study. Journal Of Hydrologic Engineering. 20(3).

[3] Estevez, E., Cabrera, M. D., Fernandez-Vera, J. R., Molina-Diaz, A., Robles-Molina, J. and Palacios-Diaz, M. D. (2016) Monitoring priority substances, other organic contaminants and heavy metals in a volcanic aquifer from different sources and hydrological processes. Science Of the Total Environment. 551 186-196.

[4] Li, Z., Li, M., Liu, X., Ma, Y. P. and Wu, M. M. (2014) Identification of priority organic compounds in groundwater recharge of China. Science Of the Total Environment. 493 481-486.

[5] Li, Z., Xiang, X., Li, M., Ma, Y. P., Wang, J. H. and Liu, X. (2015) Occurrence and risk assessment of pharmaceuticals and personal care products and endocrine disrupting chemicals in reclaimed water and receiving groundwater in China. Ecotoxicology And Environmental Safety. 119 74-80.

[6] Sui, Q., Wang, B., Zhao, W. T., Huang, J., Yu, G., Deng, S. B., Qiu, Z. F. and Lu, S. G. (2012) Identification of priority pharmaceuticals in the water environment of China. Chemosphere. 89(3) 280-286.

[7] Teijon, G., Candela, L., Tamoh, K., Molina-Diaz, A. and Fernandez-Alba, A. R. (2010) Occurrence of emerging contaminants, priority substances (2008/105/CE) and heavy metals in treated wastewater and groundwater at Depurbaix facility (Barcelona, Spain). Science Of the Total Environment. 408(17) 3584-3595.

[8] Liang, W. S.-Y. L. F. L. Y.-L. C. (2013) Determination of 12 Isomers of p-Nonylphenol in Groundwater by Gas Chromatography-Mass Spectrometry. Chinese Journal of Analytical Chemistry. 41 1699-1703.

[9] Peng, T. R., Huang, C. C., Chen, J. E., Zhan, W. J., Chiang, W. and Chang, L. C. (2016) Evaluating the Relative Importance of Groundwater Recharge Sources in a Subtropical Alluvial Plain Using Tracer-Based Ternary End Member Mixing Analysis (EMMA). Water Resources Management. 30(11) 3861-3878.

[10] Yoshioka, Y. I., Nakamura, K., Nakano, T., Horino, H., Shin, K. C., Hashimoto, S. and Kawashima, S. (2016) Multiple-indicator study of groundwater flow and chemistry and the impacts of river and paddy water on groundwater in the alluvial fan of the Tedori River, Japan. Hydrological Processes. 30(16) 2804-2816. 